\title{
Detection of intraspecific DNA polymorphism in Streptococcus salivarius subsp. thermophilus by a homologous rDNA probe
}

\author{
M. Pébay ${ }^{(*)}$, C. Colmin, G. Guédon, C. De Gaspéri, B. Decaris and J.M. Simonet \\ Laboratoire de Génétique et Microbiologie, Université de Nancy I, Faculté des Sciences, \\ B.P. 239, 54506 Vandœuvre-lès-Nancy (France)
}

\section{SUMMARY}

Three ribosomal probes from Streptococcus salivarius subsp. thermophilus were cloned. Sequence data demonstrate that their juxtaposition corresponds to an entire operon. They were used in order to study ribosomal operon number and organization. rRNA genes were shown to be clustered in the order $5^{\prime}-16 S-23 S-5 S-3$ ' and the number of rrn loci to vary within the subspecies. The smallest of the 3 probes was used for strain characterization. Substantial variability in hybridization patterns was observed among strains, resulting not only from, restriction fragment length polymorphism (RFLP) but also from the variability of ribosomal operon number.

Key-words: Operon, rDNA, rRNA, Streptococcus salivarius subsp. thermophilus; Genetic polymorphism, RFLP, Ribotyping, Probes.

\section{INTRODUCTION}

Streptccoccus salivarius subsp. thermophilus, designated as $S$. thermophilus throughout this paper, is a bacterium used in industry as a starter in the manufacture of yoghurt and certain types of cheese. Thus, strain characterization is a point of interest for dairy manufacturers. Ribotyping has already been used in species, subspecies or biotype identification (Grimont and Grimont, 1986, Grimont et al., 1989, PicardPasquier et al., 1990, Irino et al., 1988, Cox et al., 1990), and this molecular identification system is likely to be adapted to many bacterial species. Ribosomal DNA sequences are suffi- ciently conserved within bacteria to allow the use of a heterologous probe such as Escherichia coli rRNA, although signal intensities are weak and stringency conditions have to be lowered.

Nevertheless, the use of ribosomal probes, is not only of interest in strain characterization but also enables studies of ribosomal operon number and arrangement to be carried out. Indeed, the number of rRNA loci is quite different among eubacteria, ranging from 1 in slowgrowing Mycobacterium species, such as $M$. leprae (Sela et al., 1989) to 9 or 10 in Bacillus subtilis, according to strain (Widom et al., 1988). Moreover, although the arrangement of cluster-

Submitted May 13, 1991, accepted July 26, 1991.

(*) Corresponding author. 
ed genes in the order $5^{\prime}-16 \mathrm{~S}-23 \mathrm{~S}-5 \mathrm{~S}-3^{\prime}$ is that which is most frequently found, it has been shown not to be universal even in eubacteria, e.g. in Vibrio harveyi the linkage order is 5'-23S-16S-5S-3' (Lamfrom et al., 1978). In Pirellula marina, the $16 \mathrm{~S}$ genes are separated from the 23S-5S loci (Liesak and Stackebrandt, 1989), whereas in Leptospira interrogans (Fukunaga et al., 1989, 1990), the uniugse SS gene is distant from the two 16S-23S clusters ffor ieview, see Krawiec and Riley, 1990).

The use of cloned homologous $r m$ genes has some advantages over that of heterologous rRNA or rDNA, especially for studies of ribosomal operon number and organization. Indeed, restriction maps need to be known for the interpretation of hybridization patterns in terms of the number of rRNA operons. Moreover, homologous probes give rise to stronger signals whose interpretation is less ambiguous.

For this purpose we have cloned ribosomal fragments, whose juxtaposition corresponds to an entire composite rRNA operon. The smaller fragment was entirely sequenced, as were the ends of the other two. The sequenced probe was hybridized on a wide sample of $S$. thermophilus strains including industrial strains, strains from 3 different collections and the type strain ATCC19258. A high level of polymorphism was observed among these strains which was shown to be due to both restriction fragment length polymorphism (RFLP) and variability in the operon number.

\section{MATERIALS AND METHODS}

\section{Bacterial strains and culture media}

S. salivarius subsp. thermophilus strains used in this study are listed in table $\mathbf{I}$. They were grown in M17 broth medium supplemented with $5 \mathrm{~g} / \mathrm{l}$ lactose (Terzaghi and Sandine, 1975) at $42^{\circ} \mathrm{C}$ from $1 \%$ sub- cultures in reconstituted milk $(10 \%) . E$. coli JM 109 was grown in LB medium.

\section{Preparation of DNA}

A modified version of the Marmur (1961) procedure was used for the extraction of total streptococcal DNA. Modifications consisted mostly of the increase in both lysozyme concentration $(15 \mathrm{mg} / \mathrm{ml})$ and time of action $\left(2 \mathrm{~h}\right.$ at $\left.37^{\circ} \mathrm{C}\right)$. For large scale preparations, plasmids from $E$. coli were extracted by the alkaline lysis method described by Hopwood $e t$ al. (1985) and purified on a $\mathrm{CsCl}$ gradient. For minipreparations, the slkaline lysis procedure described by Maniatis et al. (1982) was used.

\section{Restriction endonuclease digestion analysis}

Restriction endonucleases purchased from Bœhringer Mannheim and New England Biolabs were used according to the suppliers' instructions.

\section{DNA cloning}

$X$ hol fragments of strain NST1403 were ligated into Xhol unique site of "pBluescript $\mathrm{KS}^{+}$" (Stratagene). The ligation mixture was used to transform E. coli JM109 by electroporation according to Dower et al. (1988). Cells were then spread on LB medium supplemented with IPTG $(38 \mu \mathrm{g} / \mathrm{ml})$, X-Gal $(32$ $\mu \mathrm{g} / \mathrm{ml})$ and ampicillin $(50 \mu \mathrm{g} / \mathrm{ml})$. Plasmidic content of white colonies was extracted by minipreparation procedure and analysed on gel. Preparative extractions were carried out on the selected clones. Plasmids suspected of containing ribosomal DNA were hybridized with plasmid pOS113, obtained from J.L. Pernodet (1985), which contains the entire $r m D$ operon of Streptomyces ambofaciens.

\section{DNA radiolabelling}

Probes were ${ }^{32} \mathrm{P}$-labelled by nick-translation (Amersham international, Amersham, UK) for plasmids or by the multiprime DNA-labelling system (Amersham) for DNA fragments purified on agarose gel by the "Geneclean" procedure (Bio 101, La Jolla, CA).

\footnotetext{
IPTG = isopropyl-\{s-thiogalactopyranoside.

$\mathrm{LB}=$ Luria-Bertani (medium).

nt $=$ nucleotide.
}

RFLP $=$ restriction fragment length polymorphism.

$\mathrm{X}$-Gal $=5$-bromo-4-chloro-3-indolyl- $\beta$-D-galactopyranoside. 


\section{Southern hybridizations}

They were carried out as previously described (Larbi et al., 1990). Washings were carried out at $60^{\circ} \mathrm{C}$ for intraspecific hybridizations, or at $45^{\circ} \mathrm{C}$ for interspecific ones. "Hyperfilm-MP" (Amersham) was exposed at room temperature or at $-70^{\circ} \mathrm{C}$ with intensifying screens for $13 \mathrm{~h}$ to 3 days.

\section{Dideoxy sequencing}

The chain-termination method was performed with the "Sequenase 2.0" sequencing kit (USB) and $\alpha-{ }^{35}$ S-dATP (Amersham). For each set of 4 reactions $1.5 \mathrm{pmol}$ of alkali-denaturated plasmid were anneal-
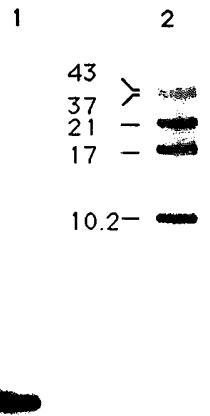

ed to 2 pmol of SK $\mathrm{c}^{-}$T3 primer (Stratagene). The labelling and chain-termination steps were carried out in the presence of either dCTP or dITP. HyperfilmMP was exposed for 2 or 3 days to soaked and dried gels. Both strands of I41 were sequenced.

\section{RESULTS}

\section{Identifieation of ribosomal probes}

Xhol fragments from strain NST1403 were cloned in the unique XhoI site of plasmid pBluescript $\mathrm{KS}^{+}$. Among the recombinant plasmids that we obtained, pNST41 was found to contain a $0.53-\mathrm{kb}$ insert, henceforth called 141 . Hybridizations of pNST41 on chromosomal DNA digests of strain NST1403 (fig. 1) revealed 5 fragments on BgI patterns and 5 fragments on HindIII patterns. Only 3 fragments were observed on PvulI patterns, but one of them was of stronger intensity than the other 2. These observations indicated that this fragment was repeated. Morsover, we noticed that fragments of similar sizes were revealed by plasmid pOS113 (Pernodet el al., 1985), which contains the entire $r r n D$ locus of $S$. ambofaciens, suggesting that the cloned DNA fragment was a part of an rRNA locus. Direct hybridization of $14 !$ on pOS 113 gave rise to a strong signal and confirmed the hypothesis. Hybridization of I41 on pOS113 digested with various restriction enzymes enabled the identification of the cloned DNA fragment as a part of the 23S rDNA gene close to the $3^{\prime}$ end (fig. 2).
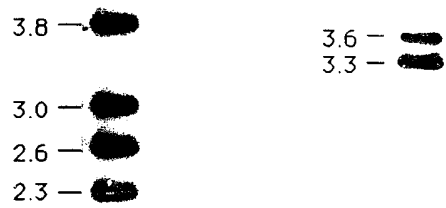

Fig. 1. Autoradiogram of strain NST1403 restriction patterns hybridized with pNST41.

Migration through $0.7 \%$ agarose gei was carried out for $15 \mathrm{~h}$ at $1 \mathrm{~V} / \mathrm{cm}$. Lane 1) HindlII pattern; lane 2) $B g / \mathrm{I}$ pattern; lane 3) PvulI pattern. Fragment sizes are given in $\mathrm{kb}$.

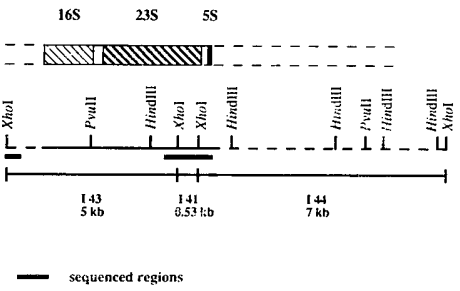

Fig. 2. Positions of $[43, I 4]$ and $I 44$ towards a ribosomal operon and locations of restriction sites used in this study. 


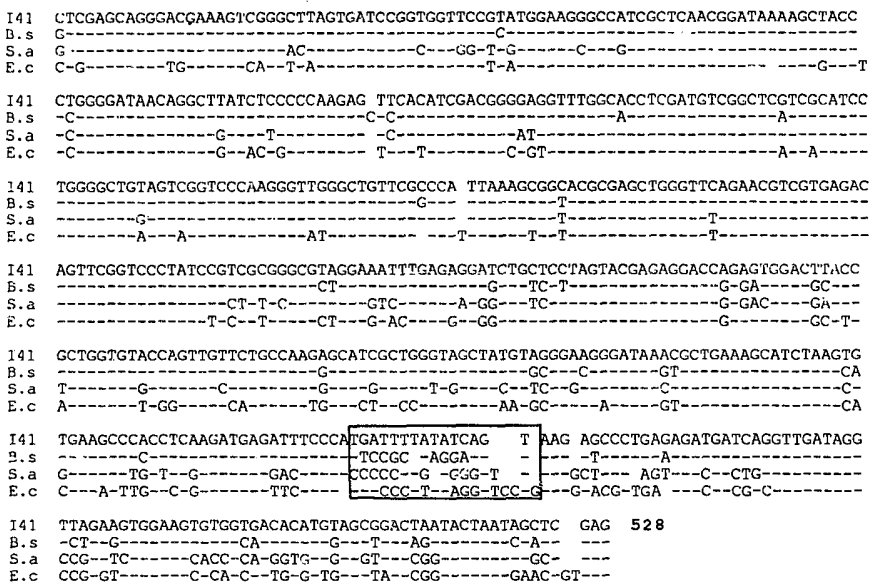

Fig. 3. Sequence of $I 41$ and its alignment with the corresponding regions of B. subtilis $r r n B$ (B.s), S. ambofaciens $r r n D$ (S a) and E. coli $r r n B$ (E.c).

The framed box corresponds to the hypervariable region (nt 429-444). Dashed lines mean same nucleotide as indicated for $\mathbf{I 4 I}$.

In order to accurately locate the $23 \mathrm{~S}$ fragment contained in pNST41, the nucleotide sequence of the cloned DNA fragment was established (fig - 3) and compared with the corresponding $B$. subtilis rrnB (Green et al., 1985), S. ambofaciens $r r n D$ (Pernodet et al., 1985) and E. coli rrnB (Brosius et al., 1981) sequences. This enabled the identification of $\mathrm{I} 41$ as the fragment corresponding to the interval nt 2362 to 2894 of 23S rRNA of $E$. coli. Percentages of homology between 141 and the corresponding sequences from $B$. $s u b$ tilis, $S$. ambofaciens and $E$. coli were 90.2, 81.3 and $76.6 \%$, respectively, and were in accordance with the generally accepted phylogeny (Stackebrandt and Teuber, 1988). Although homology between these sequences taken as a whole was very strong, it was not evenly distributed and the presence of a hypervariable region was noticed from nt 429 to nt 444 of our num- bering, corresponding to the 2789-2806 helix of E. coli 23S rRNA (Noller, 1984). The G + C \% of the whole sequence was $53 \%$. This is quite a high value for $S$. thermophilus whose total $\mathrm{G}+\mathrm{C}$ contents ranges from 37.2 to $39.8 \%$ (Farrow and Collins, 1984). This is in accordance with the general observation that $\mathrm{G}+\mathrm{C}$ contents of rRNA genes are not as variable as those of total genomes, probably reflecting sequence conservation of rDNA.

Another recombinant plasmid, pNST43, containing a 5-kb insert called I43, which, when used as a probe on chromosomal $B g I$ digests, revealed the 5 bands already revealed by 141 . Insert I43 did not cross-hybridize with I41, but it did with pOS 113 . Hybridization of $\mathbf{I 4 3}$ on various digestions of pOS113 showed that 143 contained a $16 \mathrm{~S}$ gene and part of the adjacent $23 \mathrm{~S}$ gene. Insert 143 endis were sequenced. Comparison 
with other published sequences showed that 143 was strictly contiguous to one of the 141 copies, as its other end was located upstream of the $5^{\prime}$ end of $16 \mathrm{~S}$ (fig. 2).

Plasmid pNST44 contained a 7-kb insert, called I44, which did not hybridize with I41, I43 or pOS113, whereas it hybridized on all the HindIII fragments already revealed by 141 . Among the fragments revealed by both $\mathrm{I} 41$ and 144 , only one was of strong intensity, the others were weaker. This result showed that a part of 144 was present only once in the $S$. thermophilus genome, another part being repeated close to each I4I copy and so weakly revealing all I41 copies. By sequencing its end, it was found to be exactly contiguous to one of the I41 copies and to contain the last 15 bp of a 23S rDNA, a 84-bp long spacer, and then a 5 S rDNA gene (fig. 2).

The fact that 143 contains a 16S rRNA gene and a part of the adjacent 23S rDNA gene, that I41 contains a part of a 23S rRNA gene, that I44 contains the last few bases of a 23S rRNA gene and a 5S rRNA gene and that these 3 fragments are homologous to strictly contiguous sequences, shows that the juxtaposition of the 3 cloned DNA fragments in the order I43-I41-I44 represents an entire $r r n$ operon, with the most frequently found arrangement being 5'-16S-23S-5S-3' (fig. 2). Indeed, although the 3 fragments were not cloned from the same operon, since every fragment revealed by 141 was also revealed by both 143 and I44, it implies that all the operons of strain NST1403 are likely to contain $16 \mathrm{~S}, 23 \mathrm{~S}$ and $5 \mathrm{~S}$ genes.

\section{Ribosomal operon number}

Hybridization of 141 on strain NST1403 HindIII pattern (fig. 1) revealed 5 fragments with similar intensity. According to their size (the biggesî was $5.3 \mathrm{~kb}$ long), these fragments could not contain more than one ribosomal cperon. Since no HindIII site was found in 141 , either by HindIII digestion or by sequencing, it is very likely that 141 has 5 copies in the NST 1403 genome. This hypothesis was confirmed by the
$B g /$ hybridization profile in which 5 signals were also observed. The fact that only 3 spots were revealed on the $P v u$ II pattern is compatible with this result because of the higher intensity of the 3.3-kb signal which may be a triple signal.

We therefore considered whether the 141 copy number was identical to the number of whole ribosomal operons. For this purpose we used another probe, I43, which has one PvuII and one HindIII site. According to the restriction map of this region, the number of fragments revealed by 143 was expected to be twice the number of fragments revealed by I41. Indeed, I43 revealed 5 more bands on PvuII or HindIII chromosomal digests than did 141 (data not shown). These results confinned the fact that strain NST1403 contained 5 rDNA operons.

In order to establish whether the number of ribosomal operons was constant within the subspecies $S$. thermophilus, similar work was carried out on a wide sample of strains of various origin: strains from 3 collections, including the type strain ATCC19258, and industrial strains (table I). Hybridization of 141 on HindIII pat-

Table I. S. thermophilus strains used in this study.

Strains Origin

ATCC19258, ATCC19987 ATCC

CNRZ7, CNRZ160,

CNRZ302, CNRZ307,

CNRZ308, CNRZ368,

CNRZ385, CNRZ388,

CNRZ391, CNRZ445,

CNRZ455

CNRZ

CIP6631, CIP6757

CIP

A054 ${ }^{(*)}$, NST1, NST5,

NST7, NST10, NST11,

NST12

NST 1403

Industrial strains

Obtained in the laboratory by subcloning strain CNRZ368

ATCC $=$ American Type Culture Collection, Rockeville, $M D$ (USA).

CNRZ = Centre National de la Recherche Zootechnique, Jouy-en-Josas. (France).

$\mathrm{CIP}=$ Collection de I'Institut Pasteur, Paris (France).

(*) Kindly provided by Dr. A. Mercenièr. 


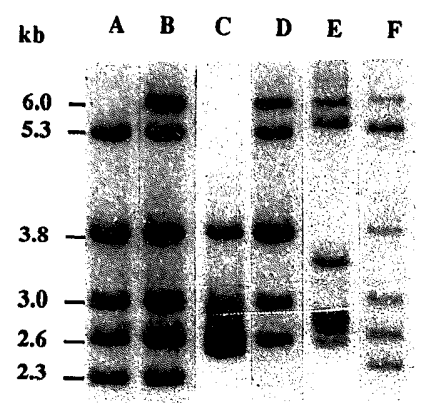

Fig. 4. Autoradiogram of HindIII digests of various $S$. thermophilus hybridized with pNST41.

Migration through $0.8 \%$ agarose gel was carried out for $15 \mathrm{~h}$ at $1 \mathrm{~V} / \mathrm{cm}$. Lanes are lettered according to table II. Lane $\mathrm{A}=\mathrm{NST} 1403$; lane $\mathrm{B}=\mathrm{CNRZ368}$; lane $\mathrm{C}=$ ATCC19258; lane D = CNRZ307; lane E = IP6631; lane

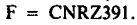

terns was realized for 23 strains and 6 types of pattern were observed (fig. 4 and table II).

Group B was made up of 16 strains which exhibited the same hybridization pattern consisting of 6 bands of similar intensity, 2.3, 2.6, 3.0, $3.8,5.3$ and $6 \mathrm{~kb}$, respectively. In strain CNRZ391 (group F), a fragment of $2.35-\mathrm{kb}$ appeared instead of the 2.3-kb fragment. Strain CNRZ307 (group D) lacked the 2.3-kb band but the 3.8-kb signal was of double intensity. In strain IP6631 (group E), the pattern was quite different, although 6 fragments were also revealed which were $2.5,2.65,2.7,3.35,5.4$ and $6 \mathrm{~kb}$ long. Hence, in these 20 strains, the 141 copy number was 6 , although we had no direct indication that the 6 copies were identical.

Conversely, in the 3 strains of group A (CNRZ7, NST1403 and A054), the I41 copy number was 5 . Indeed, fragment sizes were identical to those of group B, but the 6-kb fragment was missing and all the signals were of similar intensity. In strain ATCC19258 (group C), only

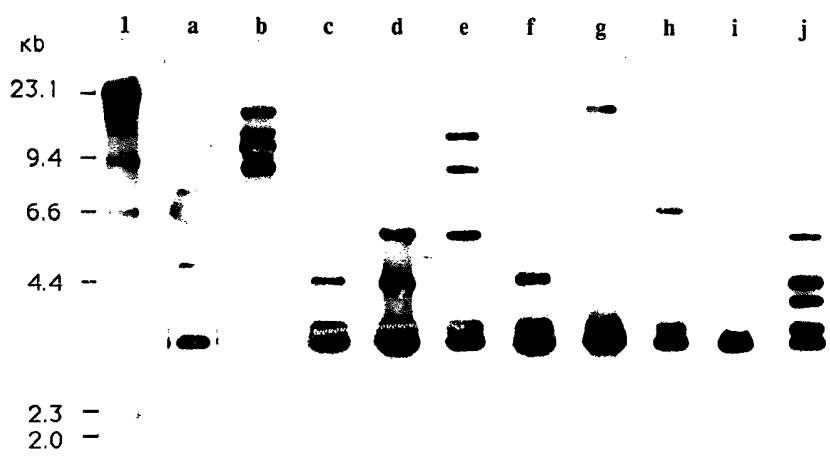

Fig. 5. Autoradiogram of Pvull digests of various $S$. thermophilus hybridized with pNST41.

Migration through $0.8 \%$ agarose gel was carried out for $17 \mathrm{~h}$ at $1 \mathrm{~V} / \mathrm{cm}$. Lanes are lettered according to table II. Lane 1: HindIII digested $\lambda$ DNA. Lane $\mathbf{a}=$ ATCC19258; lane $b=$ CNRZ385; lane $\mathrm{c}=\mathrm{NST} 11$; lane $\mathrm{d}=\mathrm{CNRZ307}$; lane $\mathrm{e}=\mathrm{CNRZ308}$; lane $\mathrm{f}=\mathrm{CNRZ391}$; lane $\mathrm{g}=\mathrm{CNRZ445}$; lane $\mathbf{h}=$ NST $1403 ;$ lane $\mathrm{i}=1 \mathrm{P} 6631 ;$ lane $\mathrm{j}=$ ATCC19987. 
4 fragments were revealed, which were $2.5,2.6$, 2.9 and $3.8 \mathrm{~kb}$ long. This pattern was quite different from the others, the two bands common to this strain and the others were the $2.6-\mathrm{kb}$ and the 3.8-kb fragments.

In order to determine whether each sequence homologous to 141 was included in a whole ribosomal operon, the 143 probe was hybridized on the HindIII pattern of at least one strain of each group. Groups $\mathrm{C}$ and $\mathrm{E}$ excepted, the results that were obtained with this probe were consistent with those obtained with I41 and gave evidence for the presence of 5 rRNA operons in group A (strains CNRZ7, NST1403 and A054) and 6 rRNA operons in groups $B, D$ and $F$. In the case of strain ATCC19258 (group C), 5 additional signals were observed on HindIII patterns hybridized with 143 instead of the 4 expected. This could be due to the presence of a HindIII site in one of the sequences homologous to I43 in strain ATCC19258. Another explanation could be that two operons close together are inverted, and so, two sequences homologous to $\mathrm{I} 4 \mathrm{l}$ would be on the same HindIII fragment. A third possibility could be the presence of a truncated operon in strain ATCC19258, perhaps only constituted by the 16S rDNA gene. In the case of strain IP6631 (group E), only two very strong additional signals of 3.8 and $6 \mathrm{~kb}$ were observed on HindIII patterns hybridized with 143 , instead of the 6 expected. This could be explained by the co-migration of several 143 homologous sequences, perhaps indicating the presence of conserved sequences upstream of the $16 \mathrm{~S}$ genes.

\section{Intraspecific polymorphism}

I41 was used as a probe on $P v u I I$ and $B g l$ I restriction patterns of 23 strains in our laboratory collection, co-migrations were realized to enable discrimination between bands of close molecular weight. Ten different Pvull patterns were revealed (fig. 5, table II). All but one shar-

Table II. Classification of strains among $P v u I I, B g I$ and $H i n d I I I$ groups based on 141 hybridization patterns.

\begin{tabular}{cccccc} 
Strains & HindIII & PvuIl & BgII & $\begin{array}{c}\text { 141 copy } \\
\text { number }\end{array}$ & Final group \\
\hline CNRZ7 & A & c & 10 & 5 & I \\
NST1403 & A & h & 9 & 5 & II \\
AO54 & A & h & 9 & 5 & II \\
NST1 & B & h & 8 & 6 & III \\
CNRZ368 & B & h & 7 & 6 & IV \\
CNRZ385 & B & b & 12 & 6 & V \\
CNRZ455 & B & c & 12 & 6 & VI \\
CNRZ302 & B & c & 2 & 6 & VII \\
CNRZ388 & B & c & 11 & 6 & VIII \\
NST11 & B & c & 11 & 6 & VIII \\
NST12 & B & c & 4 & 6 & IX \\
CIP6757 & B & c & 5 & 6 & X \\
NST5 & B & c & 5 & 6 & X \\
NST7 & B & c & 5 & 6 & X \\
NST10 & B & c & 5 & 6 & X \\
CNRZ160 & B & c & 5 & 6 & XI \\
CNRZ308 & B & e & 13 & 6 & XII \\
ATCC19987 & B & j & 16 & 6 & XIII \\
CNRZ445 & B & g & 3 & 4 & XIV \\
ATCC19258 & C & a & 6 & 6 & XV \\
CNRZ307 & D & d & 1 & 6 & XVI \\
CIP6631 & E & i & 14 & 6 & XVII \\
CNRZ391 & F & f & 15 & & \\
\hline
\end{tabular}


ed a signal at $3.3 \mathrm{~kb}$ whose intensity was generally stronger than that of the other bands, indicating that this band was double, triple or even more. The only exception was CNRZ385 which lacked this fragment, but the whole $P v u$ II pattern of this strain was of a higher molecular weight than that of the other strains. As this enzyme is methylation-sensitive (inhibited by the methylation of the internal cytosine of the recognition sequence 5'CAGCTG3'), differences in $P v u$ II hybridization patterns between strain CNRZ385 and the other strains have to be considered in terms of methylation instead of nucleotide sequence variability.

Strains ATCC19258, ATCC19987, IP6631, CNRZ445, CNRZ391, CNRZ308 and CNRZ307 also had their own $P v u$ II hybridization patterns, and each of them constituted a group on its own (table II). Conversely, the "c" group was constituted by ten strains with identical patterns. As regards the " $h$ " group, it contained 4 strains CNRZ368, NST1, A054 and NST 1403 which did not have the same 141 copy number. The most probable explanation of the fact that NST1403 and A054 apparently have the same $P$ vuII pattern as CNRZ368 and NST1, in spite of the different 141 copy number, is that the missing operon corresponds to an additional copy of the 3.3-kb fragment.

Similar experiments were carried out by hybridization of $\mathbf{I 4 1}$ on $B g I I$ patterns. The results are summarized in table II. Compilation of $\mathrm{Hin}$ dílI, $P v u I I$ and $B g I$ groupings permitted us to define 17 groups for the 23 studied strains (table II). As most of these only contained 1 strain, it is to be expected that some new patterns may be observed if other strains were tested. These results indicate a very large variability between strains of $S$. thermophilus resulting from both variation in rm loci number and RFLP detected by ribosonal probes.

\section{DISCUSSION}

Although ribotyping has already been used in species, subspecies or type identification, such a large variability between strains of a given species, as in the present study, has rarely been reported. This observation may be due, at least in part, to the choice of restriction enzymes we used. Indeed, it can be noted that RFLP was much more substantial on $B g l l$ patterns than on $H$ indIII and PvuII ones. The former enzyme does not have any sites within the ribosomal operons and generates large fragments, often greater than $15 \mathrm{~kb}$, whereas the latter enzymes each have one site and generate smaller fragments. Thus, it can be expected that RFLP is the result of extraribosomal rather than intraribosomal sequence variability. However, as many strains have their own hybridization profiles, and as very few strains were found to share the same hybridization pattern, I41 can be used as a powerful tool in strain identification; this is particularly important for industrial microorganisms.

In a previous report (Colmin et al., 1991), we described pNST21, a species-specific probe from $S$. thermophilus which also detects RFLP. Although at this time and with the strains that we tested, pNST21 does not discriminate between strains belonging to the same 141 group, the use of these two probes will enable rapid and easy identification of a strain such as $S$. thermophilus and its accurate characterization.

Another important point to consider is that the ribosomal operon number varies within $S$. thermophilus, although we do not know whether all of them are functional. As rrn loci are repeated in the genome, they can serve as sites for intrachromosomal homologous recombination, giving rise to duplications, deletions or inversions as already described for $B$. subtilis (Widom et al., 1988) and $E$. coli (Hill et al., 1990). Variations in the number of operons can result either from deletions or duplications. In $S$. thermophilus, most strains exhibit 6 of them and a few others only 5 (strains of groups $I$ and II). Moreover, strain NST1403 which has only 5 rrn loci derives from strain CNRZ368 which has 6 of them. Thus, the most probable explanation is that typical strains of $S$. thermophilus have $6 \mathrm{rrn}$ loci and that the others are deleted mutants. In the case of strain ATCC19258, the number of operons seems to be 4 or 5 , perhaps in $\curvearrowright \eta$ atypical arrangement. Moreover, hybridi- 
zation patterns of this strain are rather different from those of other strains, sharing few bands with them, and thus this type strain does not seem to be representative of $S$. thermophilus, at iteast with regard to ribosomal genes.

In $S$. thermophilus, RFLP is quite marked since 18 groups have been established among the 24 tested strains. Moreover, real RFLP is even greater than that detected with ribosomal probes, and some strains belonging to the same final group can be distinguished on the basis of their restriction profile (unpublished results). Generally speaking, RFLP could result either from point mutations altering restriction sites or from chromosomal rearrangements. In fact, one rearrangement would modify the length of many more restriction fragments than one point mutation, and so RFLP is more likely to result from genomic plasticity than from nucleotide sequence variability.

\section{Détection du polymorphisme ADN intraspécifique chez Streptococcus salivarius subsp. thermophilus par une sonde $\mathrm{ADNr}$ homologue}

Trois sondes ribosomiques de Streptococcus salivarius subsp. thermophilus ont été clonées. Des résultats de séquençage montrent que leur juxtaposition correspond à un opéron entier. Eilics ont été utilisées pour étudier le nombre et l'organisation des opérons ribosomiques. Les gènes d'AR $\mathrm{Nr}$ sont groupés dans l'ordre $5^{\prime}-16 \mathrm{~S}-23 \mathrm{~S}-5 \mathrm{~S}-3$ ' et le nombre de loci $r r n$ varie à l'intérieur de la sous-espèce. La plus petite des trois sondes a été utilisée en vue de caractériser les souches. Une grande variabilité des profils d'hybridation a été observée entre les souches, résultant non seulement du RFLP, mais ausși de la variabilité dans le nombre d'opérons ribosomiques.

Mots-clés: Opéron, ADNr, ARNr, Streptococcus salivarius sbsp. thermophilus; Polymorphisme génétique, RFLP, Ribotypage, Sondes.

\section{References}

Brosius, J., Dull, T.J., Sleeter, D.D. \& Noller, H.F. (1981), Gene organization and primary structure of a ribosomal RNA operon from Escherichia coli. J. mol. Biol., 148, 107-127.
Colmin, C., Pébay, M., Simonet, J.M. \& Decaris, B. (1991), A species-specific DNA probe obtained from Streptococcus salivarius subsp. thermophilus detects strain restriction polymorphism. FEMS Microbiol. Letters, 81, 123-128.

Cox, N., Johnston, J., Szarka, Z., Wright, D.J. \& Archard, L.C. (1990), Characterization of an rRNAgene-specific cDNA probe: applications in bacterial identification. J. gen. Microbiol., 136, 1639-1643.

Dower, W.J., Miller, J.F. \& Ragsdale, C.W. (1988), High efficiency of $E$, coli by high-voltage electroporation. Nucl. Acids Res., 16, 6127-6145.

Farrow, J.A.E. \& Collins, M.D. (1984), DNA base composition, DNA-DNA homology and long-chain fatty acid studies on Streptococcus thermophilus and Streplococcus salivarius. J. gen. Microbiol., 130, 357-362.

Fukunaga, M. \& Mifuchi, I. (1989), Unique organization of Leptospira interrogans rRNA genes. J. Bact., 171, 5763-5767.

Fukunaga, M., Horie, I. \& Mifuchi, I. (1990), Isolation and characterization of the SS rDNA gene of Leptospira inserrogans. J. Bact., 172, 3264-3268.

Green, C.J., Stewart, G.C., Hollis, M.A., Vold, B.S. \& Bott, K.F. (1985), Nucleotide sequence of the Bacillus subtilis ribosomal RNA operon, $r r n B$. Gene, 37, 261-266.

Grimont, F. \& Grimont, P.A.D. (1986), Ribosomal ribonucleic acid gene restriction patterns as potential taxonomic tools. Ann. Inst. Pasteur/Microbiol, 137B, $165-175$.

Grimont, F., Lefèvre, M., Ageron, E. \& Grimont, P.A.D. (1989), rRNA gene restriction patterns of Legionella species: a molecular identification system. Res. Microbiol., 140, 615-626.

Hill, C.W., Harvey, S. \& Gray, J.A. (1990), Recombination between rRNA genes in Escherichia coli and Salmonella typhimurium, in "The bacterial chromosome"' (K. Drlica and M. Riley) (pp. 335-340). American Society for Microbiology, Washington, D.C.

Hopwood, D.A., Bibb, M.J, Chater, K.F., Kieser, T., Bruton, C.J., Kieser, H.M., Lydiate, D.J., Smith, C.P., Ward, J.M. \& Schrempf, H. (1985), Genetic manipulation of Streptomyces: a laboratory manual. The John Innes Institute. Norwich.

Irino, K., Grimont, F., Casin, I., Grimont, P.A.D. \& the Brazilian Purpuric Fever Study Group (1988), rRNA gene restriction patterns of Haemophilus influenzae biogroup Aegyptius strains associated with Brazilian purpuric fever. J. clin. Microbiol., 26, 1535-1538.

Krawiec, S. \& Riley, M. (1990), Organization of the bacierial chromosome. Microbiol. Rev., 54, 502-539.

Lamfrom, H., Sarabhai, A. \& Abelson, J. (1978), Cloning Bentckea genes in Escherichia coli. J. Bact., 133, 354-363.

Larbi, D., Colmin, C., Rousselle, L., Decaris, B. \& Simonet, J.M. (1990), Genetic and biological characterization of nine $S$. thermophilus bacteriophages. Le Lait. $70,107+116$.

Liesack, W. \& Stackebrandt, E. (1989), Evidence for unlinked $r r n$ operons in the planctomycete Pirellu/a marina. J. Bact., 17, 5025-5030.

Maniatis, T., Fritsch, E.F. \& Sambrook, J. (1982), Moiecular cloning: a laboratory manual. Cold Spring Harbot Laboratory, New York.

Marmur, J. (1961), A procedure for the isolation of deoxy- 
ribonuclic acid from microorganisms. J. mol. Biol. 3, 208-218.

Noller, H.F. (1984), Structure of ribosomal DNA. Ann. Rev. Biochem., 53, 119-162.

Fernodet, J.L., Boccard, F., Alegre, M.T., Gagnat, J. \& Guerineau, M. (1985), Organisation and nucleotide sequence of a ribosomal gene cluster from Streptomyces ambofaciens. Gene, 79, 33-46.

Picard-Pasquier, N., Picard, B., Heeralal, S., Krishnamoorthy, R. \& Goullet, P. (1990), Correlation between ribosomal DNA polymorphism and electrophoretic enzyme polymorphism in Yersinia. J. gen. Microbiol., 136, 1655-1666.
Sela, S., Clark-Curtiss, J.E. \& Bercovier, H. (1989), Characterization and taxonomic implications of the rRNA genes of Mycobacterium ieprae. J. Bact., 171, 70-73.

Stackebrandt, E. \& Teuber, M. (1988), Molecular taxonomy and phylogenetic position of lactic acid bacteria. Biochimie, 70, 317-324.

Terzaghi, B.E. \& Sandine, W.E. (1975), Improved medium for lactic streptococci and their bacteriophages. Appl. Microbiol., 29, 807-813.

Widom, R.L., Jarvis, E.D., LaFauci, G. \& Rudner, R. (1988), Instability of rRNA operons in Bacillus subtilis. J. Bact., 170, 605-610. 